\title{
Show your support for
}

\section{Mouth Cancer Action Month November 2015}

\author{
This Sunday (1 November) sees the start of an annual \\ campaign to help saves lives. Interested? Read on...
}

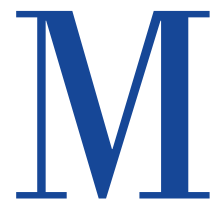

outh Cancer Action Month is taking place during November and the UK's leading oral health charity want to ensure that each and every member of the dental team is 'mouthaware'. But what does that mean?

It means being able to recognise the early signs and symptoms of mouth cancer. It means being extra vigilant with potentially high-risk patients. It means educating patients on the risk factors associated with mouth cancer and being vigilant about recognising changes in their mouth.

Organised by the British Dental Health Foundation, Mouth Cancer Action Month aims to save lives through early detection and increase education and knowledge about a disease about which awareness of still remains worryingly low.

Mouth cancer is one of the UK's fastest increasing cancers, with cases up by almost 40 per cent in the last decade alone. Dental professionals are on the frontline in the fight against mouth cancer and their support and participation remains instrumental in helping to combat a disease which kills more people every year than testicular and cervical cancer combined.

Unfortunately survival rates for those with mouth cancer have not improved in the last 20 years and it is one of the few cancers which has seen an increase in the past decade. By being 'mouthaware' and spotting mouth cancer early enough, patients are given the best possible chance to be successfully treated and have a good quality of life.

As part of every check-up dentists are required to carry out a visual examination on their patients for the early signs of mouth cancer. It is important that you know how to carry out an effective examination and also communicate with your patient what you are doing and what you are looking out for.

\section{FOLLOW THESE SEVEN SIMPLE STEPS WHEN CARRYING OUT A MOUTH CANCER CHECK:}

Head and neck - Look at the face and neck. Do both sides look the same? Look for any lumps, bumps or swellings that are only on one side of the face

Tongue - Get your patient to stick out their tongue and look at the surface for any changes in colour or texture. Gently pull out the tongue holding it with a piece of gauze and look at one side first, then the other side. Look for any swelling, change in colour or ulcers. Examine the underside of the tongue by asking the patient to place the tip of their tongue on the roof of the mouth

Neck - Feel and press along the sides and front of the patient's neck. Can you feel any tenderness or lumps?

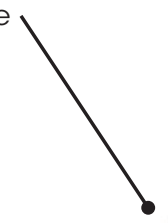

re

patches. Put your index finger patches. Put your index finger
inside the cheek and your thumb inside the cheek and your thumb
on the outside. Gently squeeze and roll the cheek to check for any lumps, tenderness or ulcers. Repeat on the other cheek

Cheek - Use your finger to pull out the cheek so that you can see inside. Look for red, white or dark
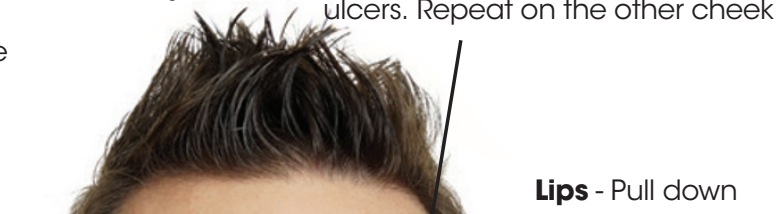
THREE TIMES AS

MANY PEOPLE

SUPPORT THE HPV

JABS FOR BOYS THAN ARE OPPOSED TO IT

Chief Executive of the British Dental Health Foundation, Dr Nigel Carter OBE, highlighted the importance of DCPs being 'mouthaware'. Dr Carter said: 'Survival rates from mouth cancer, based on an early diagnosis, are $90 \%$ compared to $50 \%$ if caught late. This is why it is so important that all dental professionals are aware of the signs, symptoms and contributing factors of mouth cancer and relay them onto patients during the visual examination part of their check-ups. men who have sex with men (MSM), it went to consultation. Peter reiterated the call to go ahead and implement this immediately.

During his speech Peter also spoke about the importance of making the right decision - not just a decision. With more than 100 senior and highly influential names supporting the decision to give the vaccination to boys, Peter said 'it is more difficult to find someone not in support of it than someone who does support it'. The level of support at a public health level is significant, yet the only people who oppose it are the bean counters.

The cost of extending the vaccination programme to boys in the UK would be relatively modest, especially now that two doses of the vaccine are required instead of three. HPV Action estimates the additional cost as being in the region of $£ 20$ - $22 \mathrm{~m}$ a year. In reality, Peter

'SIGNS OF MOUTH CANCERS INCLUDE; NON-HEALING MOUTH ULCERS, RED OR WHITE PATCHES IN THE

\section{MOUTH AND ANY UNUSUAL LUMPS OR SWELLINGS}

\section{IN THE LIPS, TONGUE, CHEEKS OR THROAT'}

'Around $90 \%$ of mouth cancers are linked to lifestyle factors and certain risk factors increase chances of developing the disease. These include smoking, alcohol and the human papillomavirus (HPV).

'Through dental professionals recognising these contributing factors in their patients they will be able to identify those most at risk and make them aware of how their lifestyle choices could be putting their health at risk.'

One of the risk factors - the human papillomavirus (HPV), is forecast to overtake smoking as the leading cause of mouth cancer within the decade. The Joint Committee on Vaccination and Immunisation (JCVI) have been considering whether to offer the HPV vaccination to boys for some time, with no significant progress made.

Keynote speaker at the launch event at the House of Commons, Peter Baker, HPV Action Campaign Director, told those gathered that there is more than enough information out there to make a decision about the vaccination and urged the JCVI to get a move on.

In the time since the JCVI began discussions on whether to vaccination boys, it could be too late for as many as $1.6 \mathrm{~m}$ boys. Peter highlighted how the JCVI's handling of the consultation is becoming 'almost Chilcot Inquiry-esq', after their decision this year to put the consultation back until 2017. Even last year when the JCVI recommended the vaccination be offered to

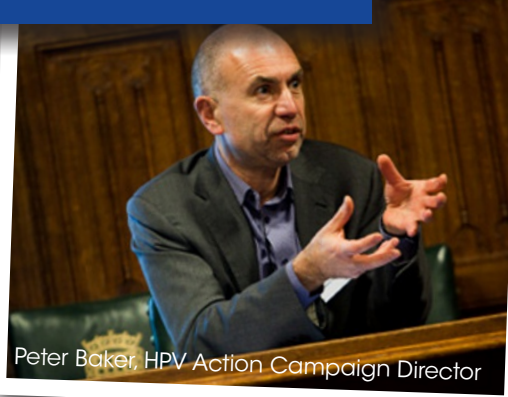

thinks it could be roughly half of this. And, to put it into context, that's half of Cristiano Ronaldo's salary.

The cost of treating each case of invasive anal cancer - also caused by HPV - from referral through to either completion of follow-up or death has been estimated at $£ 16,473$ in England; the total cost of treating just the 414 men diagnosed with anal cancer in 2011 will therefore be in the region of $£ 6.8$ million. The cost of treating RRP has been estimated at $£ 4$ million a year in the UK.

A study of the cost of treating nine major HPV-related diseases (the different cancers, anogenital warts and RRP) in Italy produced an estimate of almost $€ 530$ ( $£ 455)$ million a year; a study of the economic burden of HPV-related cancers in France estimated the cost to be about $€ 240$ (£161) million.

To register your support for the campaign, please visit www.mouthcancer.org/register

bdjteam2015155 